\title{
Effect of Demographic Variables on Information Seeking Behaviour of Company Advertising Strategies in North-Eastern Nigeria
}

\author{
Mustapha Momoh ${ }^{1}$ Mcpn, Mncs, Amnim \\ And Dr. Rachael O. Folorunso ${ }^{1}$ \\ ${ }^{1}$ Department of Business Management, University of Maiduguri, PMB 1069, Maiduguri, Borno State, Nigeria.
}

\begin{abstract}
This research contributes to the available management literature by empirically reviewing the effect of demographic variables on information seeking behaviour of company advertising strategies in North-Eastern Nigeria. Taking the entire consumers in this geopolitical zone as the universe, it investigates the demographic variables of the information seekers and non-information seekers. It specifically sampled 80 buyers in four (4) capitals cities of the six (6) state capitals in the zone. The cities selected are Bauchi, Gombe, Maiduguri and Yola for in-depth analysis. Data were presented and analysed with descriptive statistics, bar chart and MannWhitney U Test. The study found that demographic variables have considerable effect on information seeking behaviour of company advertising strategies in the North-eastern Nigeria. It also reveals that Advertising Strategic Model comprising of 'purchase attraction', 'purchase frequency' and 'awareness of product features' are determinants of information seeking behaviour in North-Eastern Nigeria. It recommends that companies should pay attention to demographic variables such as age, sex, education and occupation of the target market to make adverting effort effective and informative. It also recommends the use of Advertising Strategy Model $(A S M)$ for determining the impact of information seeking behaviour of advertising efforts in Nigeria.
\end{abstract}

Keywords: Demographic variables, Information Seeking, Behaviour, Advertising Strategy Model

\section{Introduction}

Information seeking has gained famous discourse in multidisciplinary fields of human endeavour in the last three decades. It encompasses processes of obtaining information in both human and technological contexts. However, a distinction must be drawn between information seeking information retrieval which involves tools designed for effective and efficient information retrieval from a source. Fundamentally, information retrieval dichotomy assumed that information exists in the source that is retrieved when queried. Case (2007) aptly absolved the argument that information seeking on the Web is different from information retrieval, however, web search engines are built on information retrieval principles. Literally, information retrieval can be understood as technology-oriented, focusing on issues recall, whilst information seeking may be understood as human-oriented and open-ended process to gain total understanding of a given issue. Therefore, information seeking provides a learning scene required to satisfy one's information need about a subject at a given point in time.

An extensive literature search suggests that information-seeking practices cut across various fields of profession including legal, academics, medical, engineering, and marketing among others (Kuhlthau and Tama, 2001; Brown and Ortega, 2007; Hemminger, et al, 2007; Davies and Harrison, 2007; Robinson, 2010 and Bamoriya and Singh, 2011). Interestingly, a common strap of the previous studies is built on the model of information seeking behaviour that cut across different professions. The context particularly found its relevance in the field of management sciences that is substantial information dependent for decision making.

In marketing profession for instance, information seeking is a component that makes the goals of advertisement realisable. Indeed, marketers now found information seeking behaviour as a viable utility which may influence attitude towards advertising. Bamoriya and Singh (2011) observed that individuals use advertisement for three basic reasons which include information seeking, entertainment, social expression.

As plausible as these view points, little or no empirical documentation were found in management literature on how demographic variable influences the information seeking behaviour of companies' advertising strategies in Nigeria. This study provoked by existence of this research gap investigates how demographic variables influence information seeking behaviour of company advertising strategies in North-Eastern Nigeria.

\footnotetext{
Objectives of the study are to:

i. find the determinants of information seeking behaviours of the consumers in North-Eastern Nigeria.

ii. categorise consumers into information seeking and non-information seeking continuum.

iii. study the effect of information seeking behaviour on company advertising strategies.
} 
The study hypothesised $\mathrm{H}_{0}$ that: Demographic Variables have little effect on Information Seeking Behaviour of company advertising strategies in the North-Eastern Nigeria

\section{Literature Review}

The model of information seeking behaviour popularised by Leckie, Pettigrew and Sylvain in 1996 now cut across professions, providing a frontier for further research endeavour in humanities and sciences. This model has been adapted and applied in virtually all field of specialty by scholars, like Kuhlthau and Tama (2001), Brown and Ortega (2007), Hemminger et al (2007), Davies and Harrison (2007), Robinson (2010) and Bamoriya and Singh (2011). Kuhlthau (2006) add that people experience the information search process as interplay of thoughts, feelings and actions. Information seeking behaviour is dynamic and non-linear processes for meeting information need of people. On this note, Case (2007) argued that information seeking is linked to a variety of interpersonal communication beyond question-asking. People naturally seek information either from other people and/or repositories (archives or databases). Indeed, information seekers spend substantial time receiving information passively (information that they have not requested) than actively (information they have requested). Robinson (2010) argued that people spend less time seeking information and more time in problem solving and decision making, than when consulting information repositories. His studies depicted that people spent $7.8 \%$ of work time in seeking information from other people and $6.4 \%$ from repositories, totalling $14.2 \%$ of work time. However, the distribution of time among the constituent information seeking time differs depending on presence of stimulus and behavioural tendency. Bamoriya and Singh, (2011) argued that information seekers have higher optimum stimulus level. This trait is specifically ubiquitous in effective advertisements of company products in developing economy. Similarly, Akaka et al (2010) opined that information seeking in advertisement is the omnipresent universal truth that is in modern life. Adding to this truism, Zemke, et al (2001) gave a number of behavioural characteristics of Information Seekers which include keen readers, varied materials, good accessibility, online chatting and substantial time. These behavioural tendencies depict the attitudes of consumers. It is pertinent to note that individuals' attitude towards advertising is affected by the individual experiences and belief constructs of individual about product information. In this wise, El-Adly (2010) argued that attitudes influence the way a consumer responds to advertising information.

The applicability of information seeking model to company advertising strategies can never be over emphasized. The success of company advertising strategies reflect on the level of product attraction to consumers, awareness of product features and frequency of product purchase. It is on the basis of this fact that consumer buying behaviour are classify as either 'information seekers' or 'non-information seekers'. Bamoriya and Singh (2011) suggest that advertising is either easily ignored by the individuals or is perceived to have little value if the information content is poor. Today, most marketing managers mainly focuses on the effect consumers' attitude has on successful product marketing in the light of rising cost of advertisement. A vast literature search suggests that individuals value advertisement for Information Seeking context, other variables remain constant (Bamoriya and Singh, 2011; Akaka et al, 2010 and Kumar, 2010). Indeed, through advertisements, people seek necessary, valuable information to support their purchase and to update their knowledge base relative to decision making. According to Kumar (2010), information seeking is the process of attempting to obtain information to bridge the knowledge gap of individuals and groups. Information seeking arose relative to rational problem solving process, where a gap in knowledge triggers a conscious search for information. Similarly, Bates (2002) argued that information seekers also attach high value to information accessibility, update, accurate and reliable. Laudon and Laudon (2010) argued that information is time bound. Timely information is paramount to good decision and marketers must pay attention to timing of advertisement in planning their advertising strategies. The interest of every information seekers is to bridge the current knowledge gap and seek information of interest by monitoring, browsing, searching, and querying. Bamoriya and Singh (2011) argued that in modern era advertising is experiencing eroding credibility, manipulation of facts, and promotion of materialistic values, which often cause distraction of consumer attention. Such distractions of customers' attention may lead to potential loss of lucrative markets. Evidences from the available literature shows that the processes of advertisements are lowered by factors like 'limited time' and 'high number of advertisements' competing for consumers' attention in global and local markets. Cheung et al (2007) observed that an individual's propensity to search and use information is an important construct in the analysis and explanation of consumer behaviour. Thus active information seekers generally have more positive attitude towards advertisements.

\subsection{Determinants of information seeking behaviour}

The individual's propensity to search and use information partly determines his attitude toward advertising. The motive behind different information seeking approaches may lie in the context and the person's inner processes and needs. Akihiro et al (2007) opined that informativeness and credibility of the advertising message have the greatest impact on consumers' perception. The challenge for advertising is to find ways and 
means into the consumers' perception of the brand that is acceptable and desirable (Weilbacher, 2003). Alabdali (2010) suggests a critical role of demographic variables on attitude towards advertisements. On this note, Dan et al (2008) listed demographic variables such as sex, age and education as determinants of information seeking behaviour towards advertising efforts. Bamoriya and Singh (2011) observed that individual attitudes towards advertisement stimuli can be understood from the purview of 'Optimum Stimulation Theory'. According to Schiffman and Kanuk (2010) information seekers are individuals who derived high Optimum Stimuli from advertising utility. Advertising stimuli is among the strong external stimuli and information seeking is one of the utility of advertisement, thus, information seekers who actively seek information from various sources might have a positive attitude towards advertisements. Schiffman \& Kanuk (2010) and Hoffman and Novak (1996) argued relative to Optimum Stimulation Theory that individuals with high level of stimulation are intrinsically motivated to seek information and thus maintains positive attitudes towards advertising utilities.

This study leans on 'Optimum Stimulation Level (OSL) Theory to achieve its objectives. In this wise, two typical categories of consumers on opposite ends of a continuum are delineated. At one end of the continuum, individuals with high degree of information sensitivity are identified as 'information seekers', whilst at the opposing end is 'non information seeker'.

\section{Research methodology}

This research explores the impact of information seeking behaviour on company advertising strategy in North-Eastern Nigeria. To achieve the objective, the study hypothesized that, information seeking behaviour has no significant impact on company advertising strategy in North-Eastern Nigeria. The study identified all households in the study area as the population and adopts a survey design with randomised convenience sampling technique. Data for this study was obtained by using 3points Likert-scaled structured questionnaire. It investigates the demographic variables of the information seekers and non-information seekers. The sample was evenly distributed among the respondents at urban parts of the study area, covering all categories of consumers as much as possible.

The study employed various questions to know the views and perception of the individual respondents related to purchase frequencies, purchase attraction, awareness on product features and demographic variables. Though, the researchers attempted to capture maximum sample size, due to limitation of time and respondents' cooperation, only 80 valid copies of questionnaire were retrieved from the four (4) capitals cities, out of the six (6) state capitals in the zone. The conceptualisation and development of the questionnaire was based on the existing literatures on information seeking behaviour and company advertising strategies. The questionnaire was administered with the help of 2 research assistants in selected cities of Bauchi, Gombe, Maiduguri and Yola. The study period was 3 months (November, 2012 - January, 2013).

The resultant data was subject to convergent validation test and was found to be valid as all needed indicators were found present. Data was analysed using descriptive statistics, Pie Chart and Mann-Whitney U test using SPSS 15 analytical facilities.

\section{Data Presentation and Analyses}

This chapter gathered, displays and summarises data from the survey on the basis of research objectives and hypothesis. The results from the descriptive and inferential statistics were presented and the findings are discussed. The result from Mann-Whitney U Test was used to reject the null hypothesis $\mathrm{H}_{\mathrm{o}}$, at $95 \%$ significant level. There are total of eighty (80) valid copies of questionnaire administered in four (4) sampled cities at twenty (20) per city. The distribution is as presented in table 1.

Table 1: Frequency Distribution of Responses by Information Seeking Group

\begin{tabular}{|l|c|c|c|c|}
\hline Observation & Frequency & Percent & Valid Percent & $\begin{array}{c}\text { Cumulative } \\
\text { Percent }\end{array}$ \\
\hline $\begin{array}{c}\text { Non Information } \\
\text { Seekers }\end{array}$ & 13 & $14.6 \%$ & $16.2 \%$ & $16.2 \%$ \\
\hline $\begin{array}{c}\text { Information } \\
\text { Seekers }\end{array}$ & 67 & $75.3 \%$ & $83.8 \%$ & $100.0 \%$ \\
\hline Total Valid Data & 80 & $89.9 \%$ & $100.0 \%$ & \\
\hline Missing Data & 9 & $10.1 \%$ & & \\
\hline Total & 89 & $100.0 \%$ & & \\
\hline
\end{tabular}

Table 1 presents the results of the effectiveness of company advertising strategies. Data source namely 'purchase attraction', 'awareness of product features' and 'frequency of purchase' were extracted from the field data as determinants of company advertising strategies. The result was used to categorise consumers as either 
'information seekers' or 'non information seekers'. Thus, respondents with higher scores above the mean score as presented in table 2 are the information seekers and those below the mean are non-information seekers. A total of 67 respondents rating $83.8 \%$ represent the information seekers, while 13 respondents rating $16.2 \%$ represent non-information seekers.

Table 2: Descriptive statistics of marketing Strategies result

\begin{tabular}{|l|r|}
\hline Valid Data & 80 \\
\hline Missing Data & 9 \\
\hline Mean & 6.9625 \\
\hline Minimum & 4.00 \\
\hline Maximum & 9.00 \\
\hline Sum & 557.00 \\
\hline
\end{tabular}

Highlighted in table 2 is the descriptive statistics used to categorise the consumers as information seekers and non information seekers groups. The mean score of 6.9625 was used as the benchmark for the grouping. Respondents with higher scores above the mean score through the maximum score of 9 were recoded as ' 1 ', representing 'information seekers'. Similarly, respondents with lower scores below the mean score through the minimum score of 4 were recoded as ' 0 ' representing 'non-information seekers'. The outcome was earlier presented in table 1 and the fig. 1 explains further.

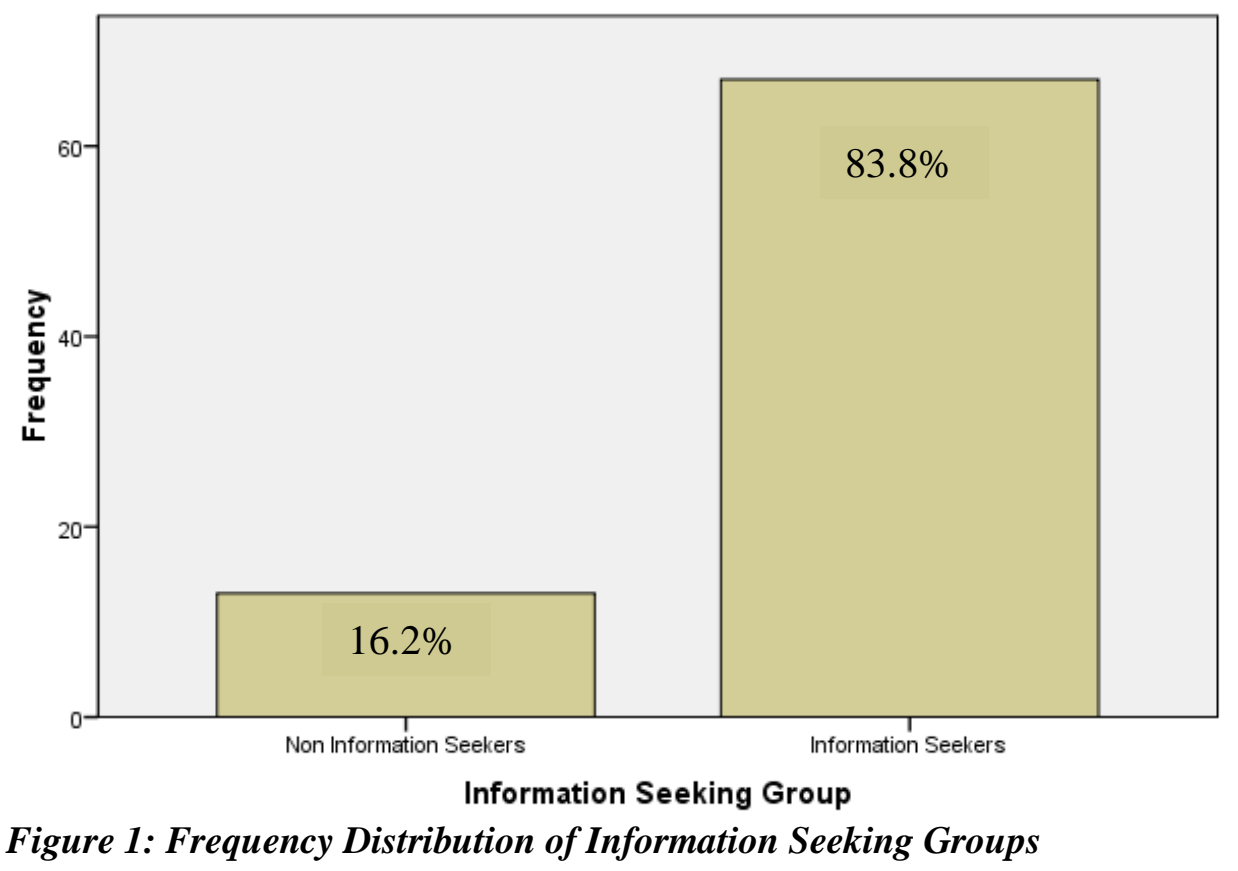

Highlighted in fig. 1 is a pictorial representation of the wide margin between information seeking group and non-information seeking group in the study area. A total of 67 respondents $(83.8 \%)$ represent the information seekers, while 13 respondents (16.2\%) represent non-information seekers. This shows that information seeking behaviour is a determinant of effective company advertising strategies in NorthEastern Nigeria. The result shows that there is high rate of purchase attraction, awareness of product features and frequency of purchase of advertised products in the zone.

\section{Test of hypothesis and findings}

Data source namely age, income, sex, education and occupation were extracted from the field data to compute the result for the demographic variable. The demographic variable is the independent (categorical) variable and the information seeking attitude is the dependent (continuous) variable required for Mann-Whitney $\mathrm{U}$ test. The values interested in mainly are the $\mathrm{Z}$ value and the significant level, which is given as Asymp. Sig (2 tailed). The fact that the sample size is larger than 30, makes it easier for the SPSS to generates a Zapproximation value, which compensates for likely ties in the data. Another important aspect of this analysis is the 'effect size statistics (r)' required to determine the weight of the relationship. The $\mathrm{r}$ is given as $Z / \sqrt{N}$ : 
where $\mathrm{N}$ is the total number of cases. The outputs generated for this test are highlighted in table3, 4 and 5.

Table 3: Mann-Whitney Test Ranks

\begin{tabular}{|cl|c|c|c|}
\hline & $\begin{array}{l}\text { Information Seeking } \\
\text { Group }\end{array}$ & $\mathrm{N}$ & Mean Rank & Sum of Ranks \\
\hline $\begin{array}{c}\text { Demographic } \\
\text { Variable }\end{array}$ & $\begin{array}{l}\text { Non Information } \\
\text { Seekers }\end{array}$ & 16 & 22.44 & 359.00 \\
& $\begin{array}{l}\text { Information Seekers } \\
\text { Total }\end{array}$ & 64 & 45.02 & 2881.00 \\
& 80 & & \\
\hline
\end{tabular}

Table 4: Test Statistics ${ }^{\mathrm{a}}$

\begin{tabular}{|c|c|}
\hline & Demographic variable \\
\hline Mann-Whitney U & 223.000 \\
Wilcoxon W & 359.000 \\
Z & -4.091 \\
R & 0.457 \\
Asymp. Sig. (2- \\
tailed)
\end{tabular}

a. Grouping Variable: Information Seeking Group

\section{Table 5: Report}

\begin{tabular}{|c|c|c|}
\hline Information Seeking Group & $\mathrm{N}$ & Median \\
\hline Non Information Seekers & 16 & 6.0000 \\
Information Seekers & 64 & 7.0000 \\
Total & 80 & 7.0000 \\
\hline
\end{tabular}

Presented in table 3 is the mean rank of the distribution between the information seeking group and noninformation seeking group. The mean rank of information seekers is 45.02 , while the mean rank of noninformation seekers is 22.44 . The mean rank of information seekers is clearly higher than the non-information seeker. The $\mathrm{Z}$ value is given in table 4 which is equal to -4.091 and $\mathrm{r}$ computed is 0.457 . The test reveals significant difference in the demographic variables of the 'information seekers' and 'non-information seekers' at $\mathrm{p}<.0005$. The median of the 'information seekers' $=7$ while the 'non-information seekers' $=6$ as shown in table 5.

With the value of $r=0.5$ (rounded), we considered an existence of large effect size using Cohen (1988) criteria of 0.1 small effect, 0.3 medium effect and 0.5 large effect. Thus, the null hypothesis $\left(\mathrm{H}_{\mathrm{o}}\right)$ which states that: 'Demographic Variables has little effect on Information Seeking Behaviour of company advertising strategies in the North-Eastern Nigeria' is rejected.

\section{Conclusions and recommendations}

The study concludes that demographic variables have large effect on information seeking behaviour of company advertising strategies in the North-eastern Nigeria. The conclusion was drawn from the result of Mann-Whitney $U$ test statistics which reveals a significant difference in demographic variables of information seekers $(M d=7, n=64)$ and non-information seekers $(M d=6, n=16), U=223, Z=-4.091, P<0.0005$ and $r=$ 0.5. This result is consistent with Pallant (2007). It also concludes that Advertising Strategy Model comprising of 'purchase attraction', 'purchase frequency' and 'awareness of product features' can be used to determined the impact of information seeking behaviour in North-Eastern Nigeria.

It recommends that companies should pay attention to demographic variables such as age, income, sex, education and occupation in the target market to make adverting effort effective and informative. It also recommends Advertising Strategy Model (ASM) for determining the impact of information seeking behaviour of advertising efforts in Nigeria. 


\section{References}

[1]. Case, D. O. (2007), Looking for Information: A Survey of Research on Information Seeking, Needs, and Behavior. Elsevier/Academic Press, MA, Boston.

[2]. Kuhlthau, C. C., and Tama, S. L. (2001), "Information search process of lawyers: A call for 'just for me' information services". Journal of Documentation, 57(1), 25-43; http://dx.doi.org/10.1108/EUM0000000007076

[3]. Brown, C. M., and Ortega, L. (2007), "Information seeking behaviour of physical science librarians: Does research inform practice". College and Research Libraries, 66(3), 231-247. http://crl.acrl.org/content/66/3/231.

[4]. Hemminger, B. M., Lu, D., Vaughan, K. T. L., and Adams, S. J. (2007), "Information seeking behaviour of academic scientists". Journal of the American Society for Information Science and Technology, 58(14), 2205-2225. http://dx.doi.org/ 10.1002/

[5]. Davies, K. and Harrison, J. (2007), "The information-seeking behaviour of doctors: A review of the evidence". Health Information and Libraries Journal 2007, 2, 78-94; http://dx.doi.org/10.1111/j.1471-1842.2007.00713.x

[6]. Robinson, M. A. (2010), "An empirical analysis of engineers' information behaviours". Journal of the American Society for Information Science and Technology, 61(4), 640-658; http://dx.doi.org/10.1002/asi.21290

[7]. Bamoriya, H. and Singh, R. (2011), "Attitude towards Advertising and Information Seeking Behaviour - A Structural Equation Modeling Approach”. European Journal of Business and Management (Online) Vol 3, No.3; www.iiste.org

[8]. Kuhlthau, C. C. (2006), "Kuhlthau's Information Search Process, in Karen E. Fisher, Sandra Erdelez, and Lynne McKechnie (Eds.)". Theories of Information Behaviour (Information Today) (pp. 230-234), New Jersey.

[9]. Akaka, M. A. and Dana, L. A. (2010), "Global Brand Positioning and Perceptions: International Advertising and Global Consumer Culture", International journal of Advertising, 29, 37-56 European Journal of Business and Management; www.iiste.org

[10]. Zemke, R., Raines, C., and Filipczak, B. (2001), "Generation Markers", www.ala.org/ala/mgrps/divs/rusa/sections/ $\mathrm{rss} / \mathrm{rsssection} / \mathrm{rsscomm} /$ virtualreference

[11]. El-Adly, M. I. (2010), "The Impact of Advertising Attitudes on the Intensity of TV Ads Avoiding Behavior", International Journal of Business and Social Science, 1 (1), 9-22

[12]. Kumar, D. (2010). "An analytical study of information seeking-behaviour among agricultural scientists in Sardar Vallabhbhai Patel University of Agriculture and Technology", http://www.academicjournals.org/ijlis/PDF/

[13]. Bates, M. (2002), "Towards an integrated model of information seeking \& searching", www.gseis.ucla.edu/faculty/bates.

[14]. Laudon, K. C. and Laudon, J. P. (2010), "Management Information Systems- Managing the Digital Firm (11th ed.)". Pearson Prentice Hall, Upper Saddle River, New Jessie.

[15]. Cheung, L., Harker, M. and Harker, D. (2007), "Consumer attitude towards advertising in general: A review of relevant literatures", www.anza.co.nz/files/anza/FAR\%20 Consumer.

[16]. Akihiro, I. and Parissa, H. (2007), "An advanced model of consumer attitudes toward advertising on the mobile internet", http://www.inderscience.com/ search/index.php

[17]. Weilbacher, W. M. (2003), "How advertising affects consumers", http\:www.erim.eur.nl/

[18]. Alabdali, O. S. (2010), "Saudi consumers' attitudes towards advertising: a contemporary perspective", http://www.inderscience.com/search/index.php.

[19]. Dan, A., Marinov M. and Marinova, S. (2008), "Consumer attitudes toward advertising in Bulgaria and Romania", http://kar.kent.ac.uk/23442/

[20]. Schiffman, L. G. and Kanuk, L. L. (2010), Consumer Behaviour, 6th edition, PHI, India European Journal of Business and Management(Online) Vol 3, No.3; www.iiste.org

[21]. Hoffman, D. L. and Novak, T. P. (1996), "Marketing in hypermedia computer mediated Environments: Conceptual foundations", http://www.jstor.org/pss/1251841

[22]. Cohen, J. W. (1988), "Statistical Power Analysis for the Behavioural Sciences (2 ${ }^{\text {nd }}$ ed)". Lawrence Erlbaum Associates, Hillsdale, NJ.

[23]. Pallant, J. (2007), "Survival Manual: A Step by Step Guide to Data Analysis SPSS for Windows (3rd Ed.)". Open University Press, McGraw-Hill Companies, New York. 